\title{
Cervical abscesses due to co-infection with Burkholderia pseudomallei, Salmonella enterica serovar Stanley and Mycobacterium tuberculosis in a patient with diabetes mellitus
}

\author{
Helmi Sulaiman ${ }^{1 *}$, Sasheela Ponnampalavanar ${ }^{1}$, Kein Seong Mun ${ }^{2}$ and Claire M Italiano ${ }^{1}$
}

\begin{abstract}
Background: Infections due to Mycobacterium tuberculosis, Burkholderia pseudomallei and non-typhoidal Salmonella cause significant morbidity and mortality throughout the world. These intracellular pathogens share some common predisposing factors and clinical features. Co-infection with two of these organisms has been reported previously but, to our knowledge, this is the first time that infection with all three has been reported in one person.

Case presentation: In September 2010, a 58-year-old diabetic Malaysian male presented with fever and a fluctuant mass on the right side of his neck. B. pseudomallei was isolated from an aspirate of this lesion and there was radiological evidence of disseminated infection in the liver and spleen. The recurrence of clinical symptoms over ensuing months prompted further aspiration and biopsy of a cervical abscess and underlying lymph nodes. Salmonella enterica serovar Stanley and then M. tuberculosis were identified from these specimens by culture and molecular methods. The patient responded to targeted medical management of each of these infections.

Conclusion: In endemic settings, a high index of suspicion and adequate tissue sampling are imperative in identifying these pathogenic organisms. Diabetes was identified as a predisposing factor in this case while our understanding of other potential risk factors is evolving.
\end{abstract}

Keywords: Melioidosis, Tuberculosis, Salmonella stanley, Diabetes

\section{Background}

Acquisition of infection requires the interplay between external factors, including environmental risk and exposure, and internal factors that contribute to host susceptibility. In tropical regions, such as Malaysia, organisms unique to the environment must always be considered in any infection. Burkholderia pseudomallei, Mycobacterium tuberculosis and Salmonella stanley are all intracellular organisms with the first two well-known for entering a latent phase in humans. A requirement for prolonged antibiotic treatment is also common to these three organisms. M. tuberculosis, one of the world's leading infectious causes of death, has an

\footnotetext{
* Correspondence: Edenhelmi@gmail.com

'Division of Infectious Diseases, Department of Medicine, University Malaya Medical Centre, Kuala Lumpur, Malaysia

Full list of author information is available at the end of the article
}

estimated incidence in Malaysia of 81 per 100000 population [1]. B. pseudomallei is a gram negative organism found in water and soil which is endemic to a number of South East Asian countries including Malaysia. Conversely, $S$. stanley is a food borne infection acquired by ingestion of contaminated food with a high incidence in neighbouring Thailand [2]. Herein, we present a case of a Malaysian diabetic male who had confirmed neck infection with these three organisms within a 6-month period.

\section{Case presentation}

In September 2010, a 58-year-old male palm oil worker from Perak state, western Peninsular Malaysia, presented with a one-week history of fever and right-sided neck swelling. No other systemic symptoms were reported and he gave no history of weight loss. On admission to

\section{() BioMed Central}


hospital, his temperature was $38^{\circ} \mathrm{C}$ and examination revealed a $5 \mathrm{~cm} \times 4 \mathrm{~cm}$ mass on the right side of his neck with overlying erythema. $2 \mathrm{~mL}$ of pus was aspirated from this fluctuant mass prior to more definitive irrigation and debridement. Though the patient had no known co-morbidities his fasting blood glucose was found to be elevated at $9.9 \mathrm{mmol} / \mathrm{L}$.

On day 2 of admission there was preliminary identification of $B$. pseudomallei from the aspirate. He was commenced on intravenous (IV) ceftazidime 2 g $3 \times$ /day and subcutaneous insulin for newly diagnosed diabetes mellitus. Computed tomography (CT) of the thorax and abdomen was performed which revealed micro-abscesses in the liver and spleen. These lesions were attributed to infection with B. pseudomallei. The patient completed a 2-week course of ceftazidime and was discharged on doxycycline $100 \mathrm{mg} 2 \times /$ day and sulfamethoxazole/ trimethoprim (cotrimoxazole) $400 \mathrm{mg} / 80 \mathrm{mg} 2 \mathrm{tab} 2 \times /$ day.

One month after discharge he was seen in clinic with a 10-day history of new left sided neck swelling. On examination, there was a $4 \mathrm{~cm} \times 4 \mathrm{~cm}$ mass and fine needle aspirate (FNA) was performed. There was no growth from the specimen sent. The patient continued on doxycycline and co-trimoxazole with no improvement in the left sided-neck swelling.

Three months after initial presentation he was readmitted and irrigation, debridement and biopsy of the neck abscess and left cervical lymph node was performed. While awaiting biopsy results he was commenced on intravenous imipenem and co-trimoxazole was increased to 4 tabs $2 \times /$ day. Doxycycline was ceased.

Biopsy of the neck abscess showed a partly ulcerated wedge of skin with pseudoepitheliomatous hyperplasia of the epidermis. The underlying dermis was infiltrated by aggregates of lymphoplasmacytic cells admixed with neutrophils and eosinophils, mostly congregating around the blood vessels and adnexae. In areas, necrotizing epithelioid granulomata (Figures 1 and 2) were seen. Langhan's giant cells were also present. Histochemistry stains with Ziehl-Neelsen (ZN) and Gomori Methanamine Silver did not reveal any acid-fast bacilli or fungal organisms. The specimen from the lymph node was revealed to be a wedge of inflamed granulation tissue.

Unfortunately, despite the need for a full microbiological diagnosis, mycobacterial culture was not requested on this specimen. However, the pus and stool cultured Salmonella species. This was later identified as Salmonella enterica serovar Stanley via polymerase chain reaction (PCR) of the pus. The patient did give a history of eating imported nuts. As he had full dentures, poor oral hygiene was not thought to be a contributing factor to this infection. He received imipenem $500 \mathrm{mg} 4 \times /$ day for 10 days followed by ciprofloxacin $750 \mathrm{mg} 2 \times /$ day. $\mathrm{He}$ was discharged on this and co-trimoxazole was

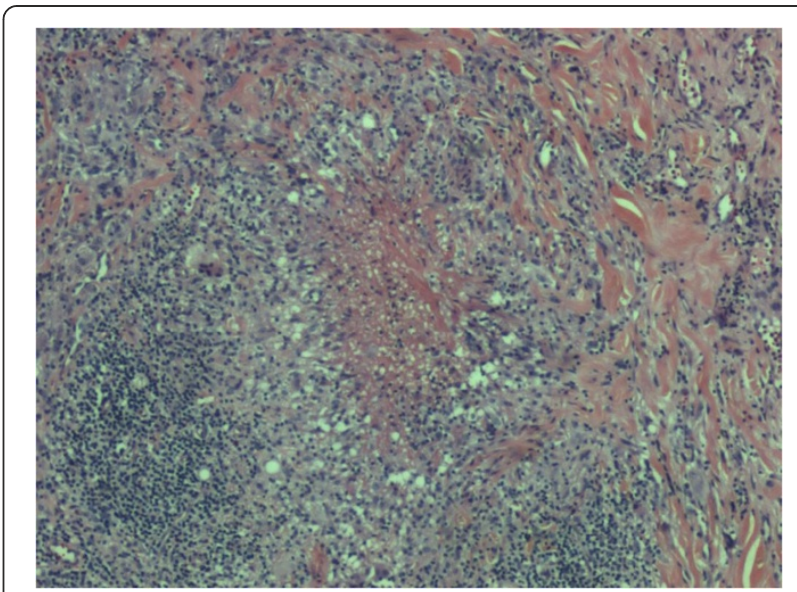

Figure 1 Histopathological specimen of the neck. This figure shows a necrotizing granuloma (Hematoxylin \& Eosin, $\times 40$ magnification).

continued. Of note, trans-thoracic echocardiogram did not reveal any vegetation on the heart valves. CT of the neck, thorax and abdomen showed that the initial right-sided neck collection had resolved, while there was a new collection in the posterior region of the left side of the neck. In addition, the liver and splenic abscesses appeared unchanged. He was negative for human immunodeficiency virus (HIV) infection.

Despite treatment for the S. stanley infection, and continuation of high dose cotrimoxazole, there remained a residual left-sided neck collection. Antibiotics were ceased and a repeat FNA was performed a week after cessation of antibiotics to investigate for tuberculosis. When this did not identify an aetiological agent, a biopsy was performed which showed only acute on

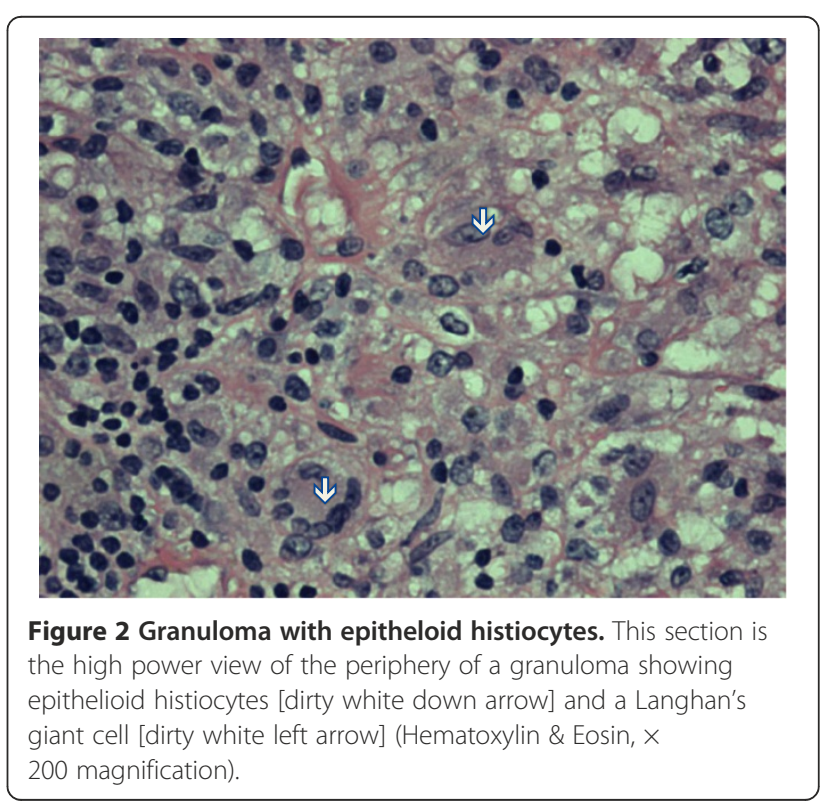


chronic inflammation. The ZN stain and mycobacterial culture were negative but PCR identified $M$. tuberculosis. The patient was commenced on isoniazid, rifampicin, pyrazinamide and ethambutol in combined tablet form to treat tuberculous lymphadenitis. His HBA1C was $7.1 \%$ on oral hypoglycaemic agents.

At review, after 1 month of treatment for tuberculosis, the left neck swelling had resolved but CT Abdomen did not show any change in the liver or splenic lesions. He completed 6 months of anti-tuberculosis treatment with no recurrence of symptoms but, despite treatment for $B$. pseudomallei, S. stanley and M. tuberculosis, there was no change in the liver or splenic lesions on repeated imaging.

At follow-up, more than 4 months after completion of all antibiotics, the patient was clinically well with no fevers or recurrence of neck swelling.

\section{Discussion}

M. tuberculosis, S. stanley, and B. pseudomallei are all intracellular pathogens with the potential for latency in the body. Though co-infection with these organisms has been reported previously, infection with all three organisms in such a short time period and with occurrence in the neck has not. All organisms are endemic to the region and this patient's work in a palm oil field is likely to have contributed to an exposure risk for $B$. pseudomallei. The patient's previously undiagnosed diabetes was the only known co-morbidity likely to increase susceptibility to these infections. Other immunological factors have been shown to predispose to these three serious infections and it may be possible that this patient had other risk factors that we were not able to investigate for.

Dual infection with $M$. tuberculosis and B. pseudomallei has been reported previously including a case presenting with a neck abscess [3-5]. In the two cases where it was documented, both patients were diabetic as in this case. Though pneumonia is the commonest manifestation of infection in both diseases [6,7], infection of the neck and regional lymph nodes is also well described $[8,9]$. A case series of infections of the neck region secondary to B. pseudomallei has previously been reported from the same region of Malaysia as where this patient resides [9]. Importantly, both infections can present in a similar manner with protracted duration of symptoms and multi-organ involvement. In fact, B. pseudomallei infection can mimic $M$. tuberculosis, and vice-versa, especially in endemic regions [10].

S. stanley is a food borne disease in which outbreaks can occur in clusters following consumption of contaminated foods such as peanuts, alfalfa sprouts, fava beans, milk and cheese [11-13]. In neighbouring Thailand, the incidence of infection with this particular serovar is high, constituting the second commonest form of infection with Salmonella species [2].

Defects in the interleukin-12 (IL12) and interferon $\gamma$ (IFN $\gamma$ ) pathway have been recognized as factors in co-infection with non-tuberculous mycobacteria and non-typhoidal salmonella [14]. IL-12 deficiency has been associated with concomitant persistent mycobacterial infection and disseminated salmonella infection [15]. IFN- $\gamma$ deficiency and autoantibodies to IFN- $\gamma$ have been linked to disseminated tuberculosis and non-tuberculous mycobacterial infection [16]. Additionally, autoantibodies to IFN- $\gamma$ have been implicated in co-infection with non-tuberculous mycobacteria and other Burkholderia species [17].

Aside from these immunological defects, diabetes mellitus is a known risk factor for all three infections and is the commonest risk factor for infection with $B$. pseudomallei in studies from Australia, Thailand and Malaysia $[6,18,19]$. B. pseudomallei is a versatile organism that is able to employ a multitude of virulence factors in order to survive in an intracellular niche. Prior to entry into cells, it has been shown that this organism can interfere with complement activity and opsonisation by phagocytes [20]. Following its acquisition it may stay dormant until the host immunity falters and favors its multiplication. This may occur in the presence of diabetes, chronic alcoholism or renal impairment. It is possible that there is interplay between diabetes and other factors that predispose to infection with intracellular organisms. Reduction in interleukin-12 production in peripheral blood monocytic cells has been shown to increase a diabetic person's susceptibility to melioidosis and tuberculosis. Unfortunately, further testing for immunological defects was not available at our institution and therefore predisposing causes other than diabetes could not be identified. In most developing and middle income countries, where these diseases are endemic, comprehensive immunological testing is not available and reinforces the need for a high degree of clinical suspicion.

B. pseudomallei and M. tuberculosis are endemic to Malaysia and the incidence of $S$. stanley infection in neighbouring Thailand is high. In this tropical environment, exposure to these organisms in this diabetic, and therefore susceptible patient, resulted in the unusual occurrence of three infections in the neck within a short time period. The diagnosis of $M$. tuberculosis must always be considered in unresolved infections and obtaining an adequate biopsy specimen to allow for identification of the organism is imperative.

\section{Conclusions}

Both tuberculosis and melioidosis may masquerade as each other due to the nature of their signs and symptoms and multi-organ involvement. However, based on our 
experience with this patient, the presence of non-typhoidal salmonellosis may also complicate the clinical picture in diabetic subjects. This underscores the importance for clinicians to have a high index of suspicion and be aware of potential infections complicating diabetes, especially in the tropics, and hence have a systematic approach to investigating and managing such patients.

\section{Consent statement}

Written informed consent was obtained from the patient for publication of this case report and any accompanying images. A copy of the written consent is available for review by the Editor of this journal.

\section{Competing interests}

The authors declare that they have no competing interests.

\section{Authors' contributions}

Both $\mathrm{Cl}$ and SP were involved in the management of the patient. The initial manuscript was prepared by $\mathrm{Cl}$. HS later contributed to the expansion of the manuscript, the analysis of the case and its discussion. KSM was involved in slide preparation, interpretation and preparation of the images of pathological specimens for the case report. All authors read and approved the final manuscript.

\section{Authors' information}

$\mathrm{HS}$ is an infectious diseases trainee in the Infectious Disease Unit at University Malaya Medical Centre. SP is a consultant in this unit while CI was a visiting consultant during this period. KSM is a pathologist and a lecturer in the pathology department of University Malaya.

\section{Acknowledgements}

This research is funded by University of Malaya Research Grant (RG 452-12HTM).

\section{Author details}

'Division of Infectious Diseases, Department of Medicine, University Malaya Medical Centre, Kuala Lumpur, Malaysia. ${ }^{2}$ Division of Anatomical Pathology, Department of Pathology, University Malaya Medical Centre, Kuala Lumpur, Malaysia.

Received: 9 July 2013 Accepted: 1 November 2013

Published: 9 November 2013

\section{References}

1. WHO report on TB prevalence in Malaysia 2013. https://extranet.who.int/sree/ Reports?op=Replet\&name=\%2FWHO_HQ_Reports\%2FG2\%2FPROD\%2FEXT\% 2FTBCountryProfile\&ISO2=MY\&LAN=EN\&outtype $=h t m l$.

2. Hendriksen RS, Le Hello S, Bortolaia V, Pulsrikarn C, Nielsen EM, Pornruangmong S, Chaichana P, Svendsen CA, Weill FX, Aarestrup FM: Characterization of isolates of Salmonella enterica serovar Stanley, a serovar endemic to Asia and associated with travel. J Clin Microbiol 2012, 50(3):709-720.

3. Azali HY, Norly S, Wong LM, Tan KS, Safian NM: Liver abscess caused by tuberculosis and melioidosis. Asian J Surg 2007, 30(2):138-140.

4. Shenoy V, Kamath MP, Hegde MC, D'Souza T, Mammen SS: Melioidosis and tuberculosis: dual pathogens in a neck abscess. J Laryngol Otol 2009, 123(11):1285-1287.

5. Shetty AK, Boloor R, Sharma V, Bhat GH: Melioidosis and pulmonary tuberculosis co-infection in a diabetic. Ann Thorac Med 2010, 5(2):113-115.

6. Hassan M, Pani S, Peng N, Voralu K, Vijayalakshmi N, Mehanderkar R, Aziz N, Michael E: Incidence, risk factors and clinical epidemiology of melioidosis: a complex socio-ecological emerging infectious disease in the Alor Setar region of Kedah, Malaysia. BMC Infect Dis 2010, 10(1):302.

7. Currie BJ, Ward L, Cheng AC: The epidemiology and clinical spectrum of melioidosis: 540 cases from the 20 year Darwin prospective study. PLoS Negl Trop Dis 2010, 4(11):e900.
8. Fitzgerald D: Mycobacterium tuberculosis. In Principles and Practice of Infectious Disease 6th, Volume 6. 6th edition. Edited by Mandell DB. Philadelphia, Pennsylvania: Elsevir Churchill Livingstone; 2005:2881.

9. Lim WK, Gurdeep GS, Norain K: Melioidosis of the head and neck. Med J Malaysia 2001, 56(4):471-477.

10. Vidyalakshmi K, Chakrapani M, Shrikala B, Damodar S, Lipika S, Vishal S: Tuberculosis mimicked by melioidosis. Int J Tuberc Lung Dis 2008, 12(10):1209-1215.

11. Werner S, Boman K, Einemo I, Erntell M, De Jong B, Lindqvist A, Lofdahl M, Lofdahl S, Meeuwisse A, Ohlen G, et al: Outbreak of Salmonella Stanley in Sweden associated with alfalfa sprouts. Euro Surveill 2007, 12(10):E071012-E071018. July-August.

12. Mahon BE, Ponka A, Hall WN, Komatsu K, Dietrich SE, Siitonen A, Cage G, Hayes PS, Lambert-Fair MA, Bean NH, et al: An international outbreak of Salmonella infections caused by alfalfa sprouts grown from contaminated seeds. J Infect Dis 1997, 175(4):876-882.

13. Pastore $R$, Schmid $H$, Altpeter $E$, Baumgartner $A$, Hachler $H$, Imhof $R$, Sudre P, Boubaker K: Outbreak of Salmonella serovar Stanley infections in Switzerland linked to locally produced soft cheese, September 2006February 2007. Euro Surveill 2008, 13(37):18979.

14. Altare F, Jouanguy $E$, Lamhamedi S, Doffinger R, Fischer A, Casanova JL: Mendelian susceptibility to mycobacterial infection in man. Curr Opin Immunol 1998, 10(4):413-417.

15. Tan KS, Lee KO, Low KC, Gamage AM, Liu Y, Tan GY, Koh HQ, Alonso S, Gan $\mathrm{YH}$ : Glutathione deficiency in type 2 diabetes impairs cytokine responses and control of intracellular bacteria. J Clin Invest 2012, 122(6):2289-2300.

16. Seneviratne SL, Doffinger R, Macfarlane J, Ceron-Gutierrez L, Amel Kashipaz MR, Robbins A, Patel T, Powell PT, Kumararatne DS, Powell RJ: Disseminated Mycobacterium tuberculosis infection due to interferon gamma deficiency: response to replacement therapy. Thorax 2007, 62(1):97-99.

17. Hoflich C, Sabat R, Rosseau S, Temmesfeld B, Slevogt H, Docke WD, Grutz G, Meisel C, Halle E, Gobel UB, et al: Naturally occurring anti-IFN-gamma autoantibody and severe infections with Mycobacterium cheloneae and Burkholderia cocovenenans. Blood 2004, 103(2):673-675.

18. Currie B: Advances and remaining uncertainties in the epidemiology of Burkholderia pseudomallei and melioidosis. Trans Roy Soc Trop Med Hyg 2008, 102:225-227.

19. Suputtamongkol Y, Chaowagul W, Chetchotisakd P, Lertpatanasuwun N, Intaranongpai S, Ruchutrakool T, Budhsarawong D, Mootsikapun P, Wuthiekanun $\mathrm{V}$, Teerawatasook N: Risk factors for melioidosis and bacteremic melioidosis. Clin Infect Dis 1999, 29:408-413.

20. Egan AM, Gordon DL: Burkholderia pseudomallei activates complement and is ingested but not killed by polymorphonuclear leukocytes. Infect Immun 1996, 64(12):4952-4959.

doi:10.1186/1471-2334-13-527

Cite this article as: Sulaiman et al: Cervical abscesses due to coinfection with Burkholderia pseudomallei, Salmonella enterica serovar Stanley and Mycobacterium tuberculosis in a patient with diabetes mellitus. BMC Infectious Diseases 2013 13:527.

\section{Submit your next manuscript to BioMed Central and take full advantage of:}

- Convenient online submission

- Thorough peer review

- No space constraints or color figure charges

- Immediate publication on acceptance

- Inclusion in PubMed, CAS, Scopus and Google Scholar

- Research which is freely available for redistribution 